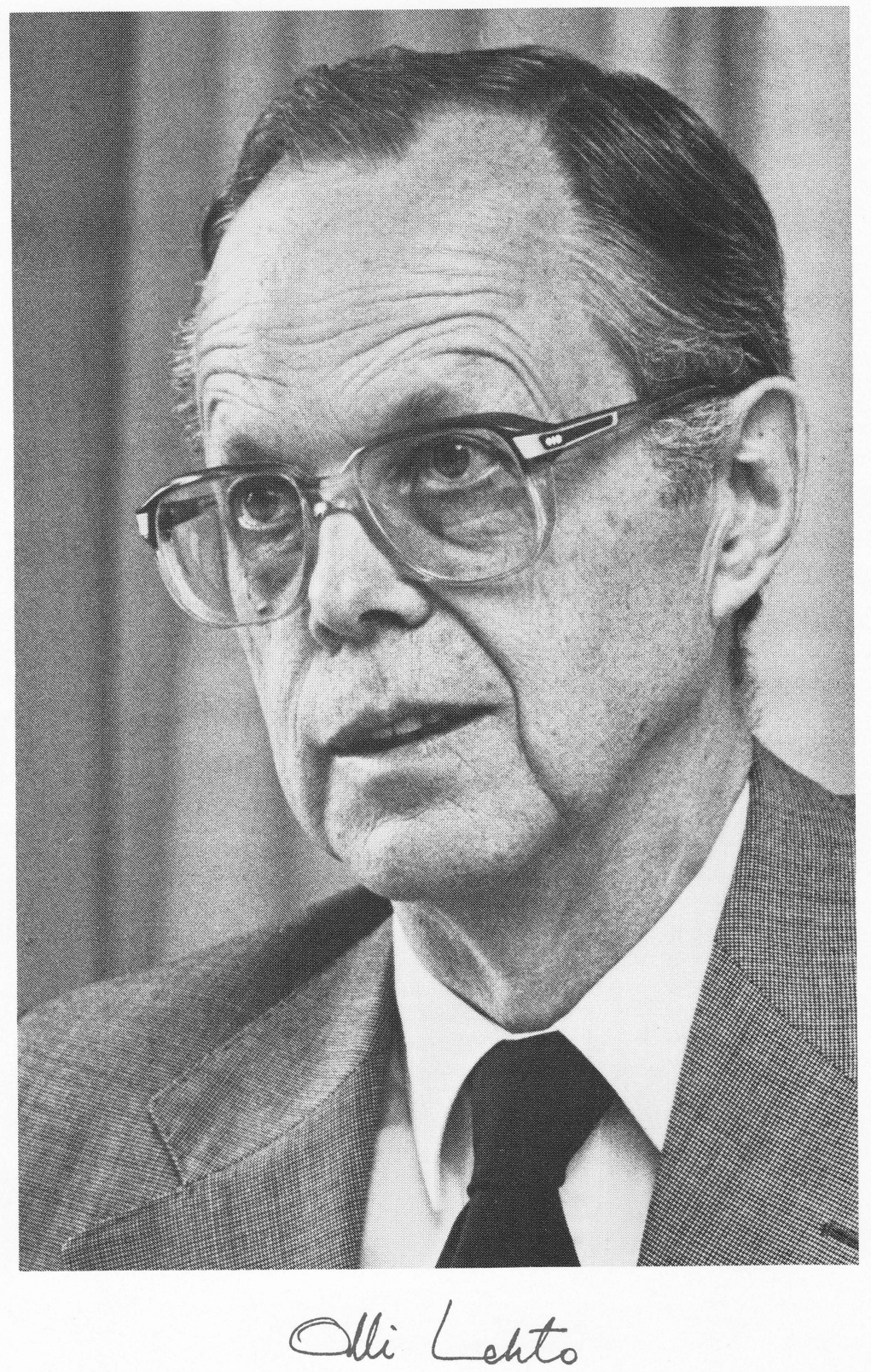

doi:10.5186/aasfm.1985.1001 


\section{OLLI LEHTO}

Our friend and colleague Olli Lehto will attain the age of sixty years on the 30th of May 1985. We are pleased to honor him with this jubilee volume as an expression of our affection for the man and respect for his manifold contributions as scholar, teacher and administrator.

Olli Lehto completed the student examination in 1943 and was then called to the Finnish army where he served until 1945. In 1949 he was awarded the Ph. D. by the University of Helsinki where he subsequently served as Docent and Associate Professor before being appointed Professor in 1961.

The remarkable achievements of the Finnish mathematicians - Lars Ahlfors, Pekka Myrberg, Rolf Nevanlinna - had dominated the field of complex analysis for over two decades prior to 1950. Hence it is no surprise that Olli Lehto followed the lead of his revered teachers and focused his research in classical function theory where he made important advances during the following ten years. Towards the end of this period he turned to the study of quasiconformal mappings. The masterful book he and his colleague Kalle Virtanen wrote in this area codified basic results and strongly influenced further investigation in the field. In addition, Olli Lehto's prolific research, stimulating publications and illuminating lectures have led to the development of an indigenous Finnish school of quasiconformal analysis whose achievements are highly esteemed by analysts throughout the world.

Olli Lehto has had great impact on present day mathematics not only as a researcher and teacher but also as an administrator. The many beautifully conducted international conferences and fruitful exchange visits which he has arranged have played an important role in broadening research activities in Finland and stimulating collaboration with colleagues abroad. That he was elected President of the Helsinki International Congress of Mathematicians in 1978 and has been asked to serve twelve years on the Executive Committee of the International Mathematical Union is evidence of how highly he is regarded by colleagues internationally.

Olli Lehto's Finnish colleagues have paid tribute to his many accomplishments by appointing him Academician in 1975, electing him Rector of the University of Helsinki in 1983 and awarding him countless fellowships and prizes. Other honors include $\mathrm{Ph}$. D. Honoris Causa from the University of Turku and Memberships in the Regia Societas Scientiarum Upsaliensis and the Kongelige Norske Videnskabers Selskab.

We join Olli Lehto's many friends and the Finnish Academy of Science and Letters in sending best wishes on the occasion of his sixtieth birthday and in wishing him continued success in his multifaceted activities.

\section{Fred Gehring}

Ilppo Louhivaara

Helsinki 15 October 1984 